\title{
HPV x câncer de colo do útero:O conhecimento das mulheres na região central de um município referência da região de saúde Ilha do Bananal-TO.
}

\section{HPV $x$ cervix cancer: the knowledge of women in the central region of a reference county of the health region of Bananal Island - TO}

Aline Gomes de Andrade 1, Layla Alves da Silva ², Cláudia Christina Guimarães Neri de Magalhães ${ }^{3}$.

\section{RESUMO}

Introdução: O Papiloma Vírus Humano, conhecido como HPV, considerado sexualmente transmissível, é um dos grandes fatores que levam ao desenvolvimento do câncer de colo do útero. As mulheres são expostas aos vírus ao longo de toda sua vida, muitas vezes sem ter o conhecimento do que causa de fato. Objetivo: Conhecer a percepção das mulheres de 20 à 24 anos sobre o câncer de colo do útero relacionado ao HPV, por meio da coleta de dados em determinada unidade de saúde na região central de Gurupi-TO. Metodologia: Estudo transversal, com abordagem quantitativa, realizado por meio de um questionário elaborado pelos pesquisadores, contendo perguntas relacionadas ao conhecimento de mulheres de 20-24 anos sobre o HPV e câncer de colo do útero. Resultados: $30,97 \%$ das entrevistadas têm 20 anos, $69,68 \%$ possui ensino médio completo, $76,13 \%$ se encontra solteira, $79,35 \%$ diz saber o que é HPV, $59,35 \%$ relata saber os sintomas, mas ao pedir para marcar algum deles $39,35 \%$ respondeu "não sei". 90,32\% conhecem o câncer de colo do útero, 50,32\% diz que o HPV não tem relação com o câncer de colo do útero e a maioria das mulheres obtiveram as informações na Unidade Básica de Saúde da Família (UBS) 31,61\%.Conclusão:O estudo observou que há falha na comunicação entre profissionais e comunidade, observa-se que as mulheres possuem uma percepção errônea, visto que a grande maioria afirma ter conhecimento sobre o vírus do HPV e o câncer, mas não identificam corretamente os sinais e sintomas e a relação entre ambos.

Descritores: Papiloma Vírus Humano. Câncer de Colo do Útero. Conhecimento.

\section{ABSTRACT}

Introduction: The Human Papilloma Virus, it is known as HPV, considered sexually transmitted, it is one of the great factors that lead to the development of cervical cancer. Women are exposed to viruses throughout their lives, mostly without having the cognition about what it causes in fact. Objective: Knowing the perception of women from 20 to 24 years of cervical cancer related to HPV, it made through the data collection in a certain health unit in the Gurupi central region- TO. Methodology: A cross-sectional study with a quantitative approach, it acomplished through a questionnaire prepared by the researchers, it containing questions related to the woman's knowledge aged 20-24 years on HPV and cervical cancer. Results: $30.97 \%$ of the interviewees are 20 years old, $69.68 \%$ have completed high school, $76.13 \%$ are single, $79.35 \%$ say they know what HPV is, $59.35 \%$ report knowing the symptoms, but when they have been asked to mark one of them $39.35 \%$ answered "I do not know". $90.32 \%$ of them are aware of cervical cancer, $50.32 \%$ say that HPV is unrelated to cervical cancer and most of the women obtained the information from the Basic Health Family Unit (UBS) $31,61 \%$. Conclusion: The study found out that there is a lack of communication between professionals and community, it is observed that women have an erroneous perception, since the vast majority claim to have knowledge about the HPV virus and cancer, but it does not identify correctly the signs and symptoms and the relationship between them.

Descriptors: Human Papilloma Virus. Cervical Cancer of theterus. Knowledge.
${ }^{1}$ Graduanda de Enfermagem da Universidade de Gurupi Unirg, $\quad$ e-mail: Aliny.andrade@hotmail.com

${ }^{2}$ Graduanda de Enfermagem da Universidade de GurupiUnirg, e-mail: lay_alvess@hotmail.com.

${ }^{3}$ Docente do curso de Enfermagem na Universidade de Gurupi - Unirg.

Endereço para correspondência:

Claudia Christina Guimarães Neri de Magalhães. Endereço: Rua Burgos, Quadra:09, Lote: 13, Jardim Sevilha, GurupiTO.Telefone: (063) 99991-0519 e-mail:

claudianeri.enfa@gmail.com 


\section{INTRODUCCAO}

O Papiloma Vírus Humano, conhecido como HPV, considerado sexualmente transmissível, é um dos grandes fatores que levam ao desenvolvimento do câncer de colo do útero (CCU), nem sempre notório. Há um desconhecimento do assunto por uma parte da população, no qual dificulta a profilaxia e forma opiniões errôneas.1 É transmitido através do contato pele a pele ou mucosas infectadas e pode causar surgimento de verrugas ou lesões, que quando não tratadas podem evoluir para vários tipos de câncer: de colo do útero, garganta ou ânus. São mais de 200 tipos de HPV, sendo que, 150 deles já foram identificados e sequenciados geneticamente. ${ }^{2}$

Pelo menos 13 dos 200 tipos podem causar lesões precursoras de câncer. Os tipos $16 \mathrm{e}$ 18 estão presentes em 70\% dos casos de câncer de colo do útero. Os HPV tipo 6 e 11 também são bastante comuns em mulheres, são considerados não oncogênicos,

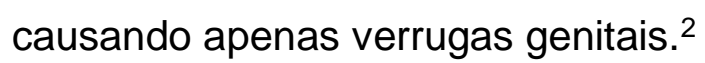

O diagnóstico geralmente é clínico, pelo surgimento de verrugas, denominadas condilomas acuminados, popularmente chamadas crista de galo, figueira ou cavalo de crista. Têm aspecto de couve-flor e tamanho variável. Nas mulheres podem aparecer no colo do útero, vagina, vulva, região pubiana, perineal, perianal e ânus. Essas lesões também podem aparecer na boca e na garganta em ambos os sexos. Pode também ser feito através do teste HPV, realizado em postos de saúde, ou exames rotineiros como papanicolau, colposcopia, vulvoscopia, peniscopia ou anúscopia.3-4Quando há presença de lesões é retirada parte do DNA e feita à biópsia para investigação de célula precursora de câncer. ${ }^{2}$

O exame citopatológico do colo do útero é o ideal para o rastreamento e detecção precoce, porém deve ser confirmado pelo exame histopatológico. A colposcopia e a biópsia dirigida são fundamentais no diagnóstico de invasão inicial, pois delimitam a extensão da doença e confirmam o diagnóstico. ${ }^{5}$

A vacinação contra o $\mathrm{HPV}$, em conjunto com 0 exame preventivo (Papanicolau/citopatológico), se complementam como ações de prevenção do câncer de colo de útero, facilitando a detecção precoce de lesões precursoras. O Ministério da Saúde implementou no calendário vacinal, em 2014, a vacina quadrivalente contra o HPV para meninas de 9 a 13 anos de idade. A partir de 2017, o Ministério da Saúde estendeu esta vacina para meninas de 14 anos e meninos de 11 a 14 anos de idade, esta faixa etária foi escolhida por ser a que apresenta maior benefício pela grande produção de 
anticorpos e por ter sido menos exposta ao vírus por meio de relações sexuais. Esta vacina protege contra os subtipos 6, 11, 16 e 18 do HPV. Os dois primeiros causam verrugas genitais e os dois últimos são responsáveis por cerca de $70 \%$ dos casos de câncer de colo do útero. ${ }^{2}$

O CCU é observado como um problema de saúde em nosso país, visto que, segundo o Instituto Nacional do Câncer (INCA)²é o terceiro tumor mais freqüente na população feminina e a quarta causa de morte de mulheres por câncer no Brasil. Sendo o HPV como um dos grandes fatores que levam a este desenvolvimento, observa-se a deficiência de conhecimento sobre o assunto por parte da população, e a necessidade de um plano educacional, visto que entre a população feminina há confusão em relação ao vírus e a identificação dos sinais.

Existe uma fase pré-clínica, ou seja, sem sintomas, do câncer do colo do útero, no qual as lesões que antecedem o aparecimento da doença podem ser detectadas através do exame preventivo (Papanicolau), que quando diagnosticado na fase inicial, permite a chance de cura de $100 \%$ do câncer de colo do útero. Conforme a doença evoluir, sintomas como sangramento vaginal, corrimento e dor podem aparecer.

A equipe multidisciplinar tem atuação fundamental na prevenção e detecção do câncer de colo do útero e da infecção pelo HPV. Promovendo educação a população para o reconhecimento precoce dos sinais de lesões precursoras, ressaltando à importância dos exames periódicos para prevenção e diagnóstico precoce, possibilitando assim um tratamento com uma boa porcentagem de cura e redução da mortalidade pela doença.

A pesquisa investigou a percepção das mulheres que residem na região central de Gurupi-TO, com a idade entre 20-24 anos sobre os sintomas mais rotineiros do HPV e sua relação com o câncer de colo do útero. Contribuindo na identificação da deficiência de informação, facilitando assim para a equipe de enfermagem uma educação mais direta, para amenizar o problema. Assim, as mulheres da comunidade passarão a ter um conhecimento mais amplo, podendo utilizar uma profilaxia adequada.

Diante de todas as informações em torno da mulher e o CCU relacionado ao HPV, é citado ainda o constrangimento para se tratar do tema de forma aberta, expondo os riscos, cuidados e ainda a patologia de forma geral.

A Unidade Básica de Saúde foi escolhida, pois de acordo com o enfermeiro responsável, abrange uma maior demanda da população alvo para a pesquisa, por atender a maior concentração das mulheres que residem no Centro de Gurupi-TO. A faixa etária escolhida (20-24 anos) foi definida por ser considerada a de maior exposição ao 
vírus do HPV, considerando a iniciação precoce da vida sexual e devido alguns fatores, como: diversos parceiros sexuais e uso incorreto da camisinha. Sendo assim, uma conscientização mais ampla, em um curto período de tempo, evitaria o grande índice de contaminação e o aparecimento das lesões precursoras do câncer.

Diante disso, o presente estudo teve como objetivo conhecer a percepção das mulheres de 20 a 24 anos sobre o câncer de colo de útero relacionado ao HPV, por meio da coleta de dados em determinada unidade de saúde na região central de Gurupi-TO.

\section{MATERIAIS E METODOS}

Tratou-se de uma pesquisa transversal com abordagem quantitativa, realizado após aprovação do Comitê de Ética e Pesquisa (CEP) sob protocolo nำ2.915.957, por meio de um questionário fechado, elaborado pelos pesquisadores, contendo perguntas claras e objetivas relacionadas ao conhecimento de mulheres entre 20 e 24 anos sobre HPV e câncer de colo do útero. As entrevistadas residem na área de abrangência da Unidade Básica de Saúde da Família João Manoel dos Santos, localizada no endereço: Rua Presidente Getúlio Vargas entre avenidas Espírito Santo e Minas Gerais, em Gurupi-TO. O período da pesquisa foi do dia 01 de outubro de 2018 a 09 de novembro de 2018.

Foram incluídas mulheres de 20 a 24 anos, que residem na área que abrange a Unidade de Saúde da Família João Manoel dos Santos, de qualquer grupo étnico e social e que possam responder por si. A faixa etária escolhida foi definida por ser considerada a de maior exposição ao vírus do HPV, que tem como consequência a iniciação precoce da vida sexual. Foi escolhida a Unidade de Saúde da Família João Manoel dos Santos por ser localização central do município em que foi realizada a pesquisa e por atender a maior concentração das mulheres que residem no Centro de Gurupi-TO.

Incluíram somente as mulheres que deram seu consentimento expresso informado para participar do estudo, de acordo com a resolução no 466 de 12 de dezembro de 2012. Os fatores de exclusão adotados foram: Mulheres que não possuem entre 20 e 24 anos, as que não estejam cadastradas na Unidade de Saúde da Família João Manoel dos Santos e as que possuem deficiência mental ou auditiva.

A amostra foi calculada através da fórmula de Barbetta $^{6}$, com o resultado de 155 mulheres, considerando a margem de erro de 5\%. Foram incluídas 252 mulheres entre 20-24 anos, cadastradas na Unidade de Saúde da Família João Manoel dos Santos.

Cada mulher foi entrevistada uma única vez, utilizando um questionário contendo 8 questões objetivas, sendo solicitado a assinatura do termo de consentimento livre e 
esclarecido. A entrevista deu-se início na Unidade de Saúde, abordando mulheres que aguardavam a consulta na recepção, em conseqüência a pouca demanda de mulheres presente na Unidade de Saúde, a abordagem foi realizada por meio de visita domiciliar agendada, utilizando o auxilio das Agentes Comunitárias de Saúde.

As variáveis coletadas foram relacionadas ao conhecimento dos sinais e sintomas do HPV e câncer de colo do útero, tais como: idade, grau de escolaridade, estado civil, conhece e saber identificar os sintomas do HPV, conhece o câncer de colo do útero, conhece a relação do câncer de colo do útero com HPV e onde foram obtidos tais conhecimentos.

Os dados finais foram analisados por meio do instrumento de consolidação de dados criado por as entrevistadoras, após análise foram submetidos a tabelas, para mostrar resultados.

\section{RESULTADOS E DISCUSSAO}

Tabela 1: Referente à idade, grau de escolaridade e estado civil.

\begin{tabular}{llc}
\hline Idade & $\mathbf{N}$ & $\%$ \\
20 anos & 48 & $30,97 \%$ \\
21 anos & 29 & $18,71 \%$ \\
22 anos & 33 & $21,29 \%$ \\
23 anos & 21 & $13,55 \%$ \\
24 anos & 24 & $15,48 \%$ \\
Total & 155 & $100 \%$ \\
Escolaridade & $\mathbf{N}$ & $\%$ \\
Ensino fundamental incompleto & & \\
Ensino fundamental completo & 01 & $0,65 \%$ \\
Ensino médio incompleto & 06 & $3,87 \%$ \\
Ensino médio completo & 16 & $10,32 \%$ \\
Ensino superior completo & 108 & $69,68 \%$ \\
Total & 24 & $15,48 \%$ \\
& 155 & $100 \%$ \\
Estado civil & & \\
& $\mathbf{N}$ & $\%$ \\
Solteira & & \\
Casada & 118 & $76,13 \%$ \\
União estável & 29 & $18,71 \%$ \\
Divorciada & 06 & $3,87 \%$ \\
Viúva & 02 & $1,29 \%$ \\
Total & 00 & $00 \%$ \\
\hline Elaborado pelas autos (2018) & 155 & \\
\hline
\end{tabular}

Fonte: Elaborado pelas autoras (2018) 
A amostra alcançada foi de 155 mulheres, todas as respostas foram validadas, somadas e convertidas para porcentagem. Após realizar a leitura dos resultados descritos na tabela 1 nota-se que há uma maior concentração na faixa etária de 20 anos, 30,97\% das entrevistadas pertencem a esse grupo. A maioria ainda, com o ensino médio completo $69,68 \%$, segundo Davim ${ }^{7}$, em seu artigo publicado, a maioria da população está direcionada a mulheres jovens em plena fase reprodutiva e de escolaridade predominante em nível médio completo. Com $76,13 \%$, seguindo ainda a tabela 1, fica centralizado um publico maior de mulheres solteiras. Em dois estudos foi identificado que esse é o estado mais predominante também em torno do mundo,a maioria das entrevistadas sempre se declara solteiras. ${ }^{8-9}$

Tabela 2: Mostra o conhecimento das mulheres em relação ao HPV e aos sintomas.

\begin{tabular}{lcc}
\hline Sabe o que é HPV? & $\mathbf{N}$ & $\%$ \\
Sim & 123 & $79,35 \%$ \\
Não & 32 & $20,65 \%$ \\
Total & $\mathbf{1 5 5}$ & $\mathbf{1 0 0 \%}$ \\
& & \\
Conhece os sintomas? & $\mathbf{N}$ & $\%$ \\
Sim & 92 & $56,35 \%$ \\
Não & 63 & $40,65 \%$ \\
Total & $\mathbf{1 5 5}$ & $\mathbf{1 0 0} \%$ \\
& & \\
Quais os sintomas? & $\mathbf{N}$ & $\%$ \\
Verrugas vaginas & 58 & $37,42 \%$ \\
Feridas vaginas & 22 & $14,19 \%$ \\
Corrimento & 12 & $7,74 \%$ \\
Dor na relação sexual & 01 & $0,65 \%$ \\
Dor baixo ventre & 00 & 00 \\
Coceira & 01 & $0,65 \%$ \\
\end{tabular}




\begin{tabular}{lcc}
\hline Dor ao urinar & 00 & 00 \\
Não sei & 61 & $39,32 \%$ \\
Total & $\mathbf{1 5 5}$ & $\mathbf{1 0 0}$
\end{tabular}

Fonte: Elaborado pelas autoras (2018)

Tabela 3: $\mathrm{O}$ conhecimento das mulheres em relação ao $\mathrm{CA}$ de útero.

\begin{tabular}{lcc}
\hline Conhece o câncer do colo de útero? & N & $\%$ \\
Sim & 140 & $90,32 \%$ \\
Não & 15 & $9,68 \%$ \\
& & \\
Total & $\mathbf{1 5 5}$ & $\mathbf{1 0 0 \%}$ \\
\hline
\end{tabular}

Fonte: Elaborado pelas autoras (2018)

Tabela 4: Estudo da relação HPV e CA de útero.

\begin{tabular}{lcc}
\hline O HPV tem relação com o CCU? & N & $\%$ \\
Sim & 77 & $49,68 \%$ \\
Não & 78 & $50,32 \%$ \\
Total & & \\
\hline
\end{tabular}

Fonte: Elaborado pelas autoras (2018)

Tabela 5: Locais aonde obtiveram as informações respondidas.

\begin{tabular}{lcc}
\hline Onde obteve essa informação? & $\mathbf{N}$ & $\%$ \\
UBS & 49 & $\mathbf{3 1 , 6 1 \%}$ \\
Casa & 25 & $16,13 \%$ \\
Amigos & 28 & $18,07 \%$ \\
Faculdade & 10 & $6,45 \%$ \\
Internet & & \\
\hline
\end{tabular}




\begin{tabular}{lcc}
\hline Outros & 24 & $15,48 \%$ \\
& 19 & $12,26 \%$ \\
Total & $\mathbf{1 5 5}$ & $\mathbf{1 0 0 \%}$ \\
\hline
\end{tabular}

Fonte: Elaborado pelas autoras (2018)

Ao perguntar sobre o HPV 79,35\%das entrevistadas afirmaram conhecer, ao indagar sobre os sintomas $59,35 \%$ responderam que sim, sabem quais são, mas ao aprofundar e pedir para assinalar algum deles $39,35 \%$ responderam apenas "não sei". Souza, Costa10 fala que as participantes de sua pesquisa demonstraram em suas respostas 0 desconhecimento sobre o vírus, já ouviram falar, mas não sabem de fato o que é.

Em relação de câncer de colo do útero 90,32\% afirmam conhecera patologia. Mas 50,32\% citam que o HPV não tem relação com o mesmo, ainda na pesquisa de Souza, Costa $^{10}$ é analisado como consequência da falta de informações coerentes sobre o HPV, muitas concepções equivocadas são desenvolvidas. As mulheres sabem que o câncer de colo do útero existe, porém não reconhece as suas causas.

$31,61 \%$ relatam ter obtido a informação na UBS. Os profissionais de saúde, devem enfatizar à população a importância de adotar estratégias de prevenção. ${ }^{11}$ De modo que esclareça cada vez mais esse tema, para assim, futuramente os índices diminuírem

\section{CONSIDERACOOES FINAIS}

É evidente a necessidade de uma comunicação clara e acessível sobre HPV e a sua relação com o câncer de colo do útero dentro da Unidade Básica de Saúde, que é considerada a maior fonte de informação para a comunidade e também carrega consigo a obrigatoriedade de levar conhecimento e prevenção.

O estudo observou que há falha na comunicação, observa-se que as mulheres possuem uma percepção errônea, visto que a grande maioria afirma ter conhecimento sobre o vírus do HPV e o câncer, mas não identificam corretamente os sinais e sintomas e a relação entre ambos.

Nota-se que ainda há imprecisão nas distribuições de informações, muitas mulheres confundem o HPV com as demais IST's (Infecções Sexualmente Transmissíveis). É notório a falta de clareza dos profissionais de saúde, que muitas vezes ao palestrar para a comunidade dispõe conteúdos excessivos, que ao invés de educar tende a confundir. 
Considerando o alto índice do CCU, observa-se a necessidade de um plano educacional por parte da equipe de saúde, fortalecendo o vínculo com a comunidade feminina e contribuindo na prevenção e detecção precoce. As informações que as mulheres recebem precisam ser filtradas e as dúvidas esclarecidas. Para reduzir o nível elevado de CCU é necessário mudar a didática, aproveitar as consultas de enfermagem, $o$ atendimento em procedimentos e principalmente as palestras para a comunidade para enfatizar o assunto e sanar as dúvidas, buscando sempre uma linguagem menos técnica, para que haja total entendimento.

\section{REFERÉNCIAS}

1. Sousa LB, Pinheiro AKB, Barroso MGT. Ser mulherportadora do HPV: uma abordagem cultural. Rev EscEnferm USP. 2008 Dez; 42(4):737-43.

2. INCA, HPV e Cancêr. $2017 . \quad$ Disponivel em: $<$ http://www2.inca.gov.br/wps/wcm/connect/tiposdecancer/site/home/colo_utero/hpv-cancer-perguntasmais-frequentes>. Acesso em: 15 de fevereiro de 2018, 10: 05: 00.

3. Lindel $\mathrm{K}$ et al. Human papillomavirus positive squamous cell carcinomaof the oropharynx: a radiosensitive subgroup of head and neck carcinoma. Cancer. 2001:95(4);805-13.

4. Santos, NOS, Romanos MTV, Wigg MD.Introdução à virologia humana. 3 ed. Rio de Janeiro: Guanabara Koogan; 2015.

5. Pinho AA, Junior IF. Prevenção do câncer de colo do útero: um modelo teórico para analisar o acesso e a utilização do teste de papanicolaou. Revista Brasileira Materno Infantil, 2003.

6. Babertta PA. Estatística aplicada a ciências socias, 5.ed, editora da UFSC, cap 3, pag.60, ano 2005.

7. DavimRMB,TorresGV, SilvaRAR, SilvaDARS. Conhecimento de mulheres de uma Unidade Básica de Saúde da cidade de Natal/RN sobre o exame de Papanicolau. Rev. esc. enferm. USP v.39 n.3 São Paulo set. 2005.

8. Cirino FMSB, Nichiata LYI, Borges ALV. Conhecimento, atitude e práticas na prevenção do câncer de colo uterino e hpv em adolescentes. Esc. Anna Nery vol.14 n.1 Rio de Janeiro Jan./Mar, 2010.

9. Carvalho RS, Nunes RMV, Oliveira JD, Davim RMB, Rodrigues ESRC, Menezes PCM. Perfil preventivo do câncer de colo uterino em trabalhadoras da enfermagem. Rev enferm UFPE online, Recife, 11(6):2257-63, jun., 2017.

10. Souza AF, Costa LHR. Conhecimento de Mulheres sobre HPV e Câncer do Colo do Útero após Consulta de Enfermagem. Revista Brasileira de Cancerologia 2015; 61(4): 343-350.

11. Thum M, Heck RM, Soares MC, Deprá AS. Câncer de colo uterino: percepção das mulheres sobre prevenção. CiencCuidSaude 2008 Out/Dez; 7(4):509-516. 